\title{
Buoyancy Driven Heat Transfer in Cavities Subjected to Thermal Boundary Conditions at Bottom Wall
}

\author{
Aswatha $^{1 \dagger}$, C.J. Gangadhara Gowda ${ }^{2}$, S.N. Sridhara ${ }^{3}$ and K.N. Seetharamu ${ }^{4}$ \\ ${ }^{1}$ Department of Mechanical Engineering, Bangalore Institute of Technology, Bangalore, Karnataka, 560 004, INDIA \\ ${ }^{2}$ Department of Mechanical Engineering, PES College of Engineering, Mandya - 571 401, INDIA \\ ${ }^{3}$ Rotary Machinery Division, M. S. Ramaiah School of Advanced Studies, Bangalore - 560 054, INDIA \\ ${ }^{4}$ Department of Mechanical Engineering, PES Institute of Technology, Bangalore - 560 085, INDIA \\ $\dagger$ Corresponding Author Email: aswath_bit@yahoo.co.in
}

(Received March 26, 2010; accepted July 12, 2010)

\begin{abstract}
Natural convection in cavities is studied numerically using a finite volume based computational procedure. The enclosure used for flow and heat transfer analysis has been bounded by adiabatic top wall, constant temperature cold vertical walls and a horizontal bottom wall. The bottom wall is subjected to uniform/sinusoidal/linearly varying temperatures. Nusselt numbers are computed for Rayleigh numbers (Ra) ranging from $10^{3}$ to $10^{7}$ and aspect ratios $(\mathrm{H} / \mathrm{L}) 0.5$ and 1 . Air is taken as working fluid $(\mathrm{Pr}=0.7)$. Results are presented in the form of stream lines, isotherm plots and average Nusselt numbers. It is observed from this study that the uniform temperature at the bottom wall gives higher Nusselt number compared to the sinusoidal and linearly varying temperature cases. The average Nusselt number increases monotonically with Rayleigh number for both aspect ratio 1 and 0.5 for bottom wall and side walls. For the case of aspect ratio 1, the average Nusselt number for a given Rayleigh number increases at the bottom wall compared to aspect ratio 0.5 . However, the average Nusselt number increases as the aspect ratio decreases from 1 to 0.5 for side wall except for uniform temperature case.
\end{abstract}

Keywords: Natural convection, Cavities, Aspect ratio, Thermal boundary conditions, Numerical heat transfer.

\section{NOMENCLATURE}

\begin{tabular}{|c|c|}
\hline$A R$ & aspect ratio $(H / L)$ \\
\hline$g$ & acceleration due to gravity $\left(\mathrm{m} \mathrm{s}^{-2}\right)$ \\
\hline$H$ & height of the cavity $(\mathrm{m})$ \\
\hline$k$ & thermal conductivity $\left(\mathrm{W} \mathrm{m}^{-1} \mathrm{~K}^{-1}\right)$ \\
\hline$L$ & length of the cavity (m) \\
\hline$N u$ & local Nusselt number \\
\hline$p$ & dimensional pressure $(\mathrm{Pa})$ \\
\hline$P r$ & prandtl number \\
\hline$q$ & heat flux $\left(\mathrm{W} \mathrm{m}^{-2}\right)$ \\
\hline$R^{2}$ & regression coefficient \\
\hline$R a$ & Rayleigh number \\
\hline$T$ & temperature $(\mathrm{K})$ \\
\hline$T_{c}$ & temperature of cold vertical wall $(\mathrm{K}$ \\
\hline
\end{tabular}

\section{INTRODUCTION}

Over past two decades, a revolution in electronics has taken place. All electronic components are sources of heat generation. Surrounding temperature of the electronic components will be within the prescribed limit in order to achieve the optimal performance. Electronic components are usually mounted on the vertical boards which form channels or cavities and the heat generated by the components is removed by a

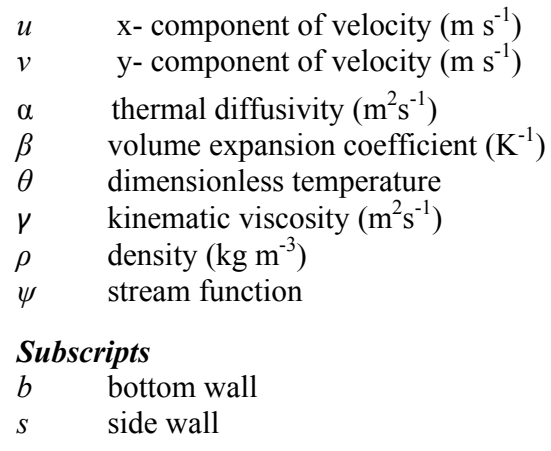

naturally induced flow of air (Dehghan and Behnia 1996). Thermally induced buoyancy forces for the fluid motion and transport processes generated in an enclosure is gaining much importance because of practical significance in science and technology. The topic of natural convection in enclosures is one of the most active areas in heat transfer research today. The current study is the prototype of many industrial and engineering applications such as cooling of electronic equipments, meteorology, geophysics, operations and 
safety of nuclear reactors, energy storage, fire control, studies of air movement in attics and greenhouses, solar distillers, growth of crystals in liquids etc. Most of the early investigations of these problems are reviewed by Cotton (1978), Jaluria (1980), Ostrach (1988) and Yang (1988). Sarris et al. (2002) studied the effect of sinusoidal top wall temperature variations within a square cavity. It has been reported that the sinusoidal wall temperature variation produces uniform melting of metals such as glass. Buoyancy driven flows are complex because of essential coupling between the flow and thermal fields. In particular, internal flow problems are considerably more complex than external ones (Basak et al. 2006). Heat transfers in enclosures with non-uniform temperature distributions on the walls are dealt in Erenburg et al. (2003), Leong et al. (1999) and Wakashima and Saitoh (2004).

In the literature, investigations on natural convection heat transfer reported that the heat transfer occurs in an enclosure due to the temperature differences across the walls. Natural convection between two vertical plates with different temperatures in which the air is used as a working fluid has been studied by Eckert and Carlson (1961). Heat transfer across the vertical layers is dealt in Emery and Chu (1965). Natural convection in horizontal cylinders has been investigated by Weinbaum (1964) and Ostrach (1970). Shallow cavity with differentially heated end walls is dealt by Cormack et al. (1974). The natural convection of air in enclosures or channels either uniformly heated/cooled or discretely heated have received much attention (Chadwick et al. 1991; Refai et al. 1991). Basak et al. (2006) have reported the effect of temperature boundary conditions (Constant temperature and sinusoidally varying) on the bottom wall for Ra varying from $10^{3}$ to $10^{5}$ for both the Prandtl numbers of 0.7 and 10 . The temperature of side walls as well as bottom wall affects the stratification rates and flow patterns (Dixit and Babu 2006).

Perusal of prior numerical investigations by Lage and Bejan (1991, 1993), Nicolette et al. (1985), Hall et al. (1988), Xia and Murthy (2002) reveals that several attempts have been made to acquire a basic understanding of natural convection flows and heat transfer characteristics in enclosures. However, in most of these studies, one vertical wall of the enclosure is cooled and another one heated while the top and bottom walls are insulated. Recently, Lo et al. (2007) studied convection in a cavity heated from left vertical wall and cooled from opposite vertical wall with both horizontal walls insulated for temperature thermal boundary conditions using differential quadrature method. Numerical results are reported for several values of both width-to-height aspect ratio of enclosure and Raleigh number. Corcione (2003) studied natural convection in a rectangular cavity heated from below and cooled from top as well as sides for variety of thermal boundary conditions. Numerical results are reported for several values of both aspect ratios of enclosure and Rayleigh numbers.

It has been observed from the literature that most of the study on natural convection in a cavity is extended up to $\mathrm{Ra}=10^{7}$ and considered air as a working fluid.
Basak et al. (2006) have studied for Ra $10^{3}$ to $10^{5}$ only for the cases of constant temperature and sinusoidally varying temperature at the bottom wall. However, in the present investigation the studies are extended up to $\mathrm{Ra}=10^{7}$ and linearly varying temperature bottom wall is included for the range of Ra studied. Recently, Basak et al. (2006) have used Galerkin finite element method to study effect of thermal boundary conditions on natural convection flows within a square cavity. In this study, the finite temperatures discontinuities are avoided at both sides by choosing non-uniform temperature distribution along the bottom wall.

The objective of the present work paper is to document the flow and heat transfer characteristics in a cavity subjected to uniform, sinusoidal and linearly varying temperature at the bottom wall, symmetrically cooled side walls with uniform temperature and insulated top wall for the range of $\mathrm{Ra}$ from $10^{3}$ to $10^{7}$ and aspect ratios of 0.5 and 1.0 .

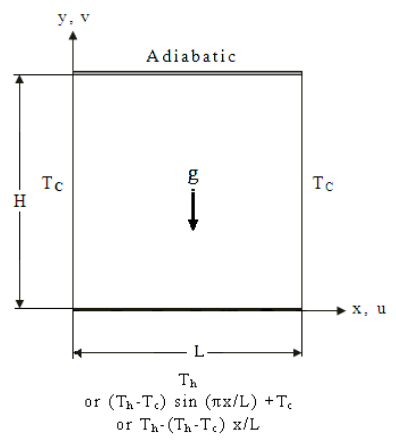

Fig. 1. Geometry of the cavity

\section{MATHEMATICAL FORMUlation}

A cavity as illustrated in Fig. 1 is chosen for simulating natural convective flow and heat transfer characteristics. The cavity of length (L) has a hot bottom wall with hot uniform/sinusoidal/linearly varying temperatures, two cold vertical walls are at constant temperature $T_{c}$ and the top wall is adiabatic. The gravitational force is acting downwards. A buoyant flow develops because of thermally induced density gradient. Heat is transferred from the hot wall to cold walls.

The governing equations for natural convection flow are conservation of mass, momentum and energy (Basak et al. 2006) which are written as:

Continuity:

$\frac{\partial u}{\partial x}+\frac{\partial v}{\partial y}=0$

$\mathrm{X}$-momentum:

$u \frac{\partial u}{\partial x}+v \frac{\partial u}{\partial y}=-\frac{1}{\rho} \frac{\partial p}{\partial x}+\gamma\left(\frac{\partial^{2} u}{\partial x^{2}}+\frac{\partial^{2} u}{\partial y^{2}}\right)$

Y-momentum:

$u \frac{\partial v}{\partial x}+v \frac{\partial v}{\partial y}=-\frac{1}{\rho} \frac{\partial p}{\partial y}+\gamma\left(\frac{\partial^{2} v}{\partial x^{2}}+\frac{\partial^{2} v}{\partial y^{2}}\right)+g \beta\left(T-T_{c}\right)$ 
Energy:

$u \frac{\partial T}{\partial x}+v \frac{\partial T}{\partial y}=\alpha\left(\frac{\partial^{2} T}{\partial x^{2}}+\frac{\partial^{2} T}{\partial y^{2}}\right)$

No-slip boundary conditions are specified at all walls.

Bottom wall:

$T(x, 0)=T_{h}$

Or

$$
T(x, 0)=\left(T_{h}-T_{c}\right) \sin \left(\frac{\pi x}{L}\right)+T_{c}
$$

Or

$$
T(x, 0)=T_{c}+\left(T_{h}-T_{c}\right) \frac{x}{L}
$$

Top wall:

$\frac{\partial T}{\partial y}(x, H)=0$

Side walls:

$T(0, y)=T(L, y)=T_{c}$

where $x$ and $y$ are the dimensional co-ordinates along horizontal and vertical directions respectively. Here, the fluid is assumed to be Newtonian and the properties are constant. Only the Boussinesq approximation is invoked for the buoyancy term.

The changes of variables are as follows:

$\theta=\frac{T-T_{c}}{T_{h}-T_{c}} ; \operatorname{Pr}=\frac{v}{\alpha} ; R a=\frac{g \beta\left(T_{h}-T_{c}\right) L^{3} \operatorname{Pr}}{v^{2}}$

In the present investigation, the geometry has been created and discretized using Gambit 2.4. Fluent 6.3 CFD package is used to simulate the natural convection of air in cavities. The effect of various temperature boundary conditions at the bottom wall (like uniform/sinusoidal/linear temperature) with constant temperature side cold walls and top adiabatic wall are studied for various Raleigh numbers. The finite discontinuity in temperature distribution appeared at the corners of the bottom wall during uniform temperature bottom wall boundary condition.

\section{Stream Function and NusSElt NUMBER}

\subsection{Stream Function}

The fluid motion is displayed using the stream function $\Psi$ obtained from velocity components $u$ and $v$. The relationship between stream function, $\Psi$ (Batchelor 1993) and velocity components for two dimensional flows are;

$u=\frac{\partial \psi}{\partial y}$ and $v=-\frac{\partial \psi}{\partial x}$

This leads to a single equation: $\frac{\partial^{2} \psi}{\partial x^{2}}+\frac{\partial^{2} \psi}{\partial y^{2}}=\frac{\partial u}{\partial y}-\frac{\partial v}{\partial x}$

Using the above definition of the stream function, the positive sign of $\Psi$ denotes anticlockwise circulation and the negative sign of $\Psi$ indicates clockwise circulation

\subsection{Nusselt Number}

In order to determine the local Nusselt Numbers, the temperature profiles are fit with quadratic, cubic and biquadratic polynomials and their gradients at the walls are determined. It has been observed that the temperature gradients at the surface are almost the same for all the polynomials considered. Hence only a quadratic fit is made for the temperature profiles to extract the local gradients at the walls to calculate the local heat transfer coefficients from which the local Nusselt numbers are obtained. Integrating the local Nusselt number over each side, the average Nusselt number for each side is obtained as

$\overline{\mathrm{Nu}_{\mathrm{b}}}=\int_{0}^{L} \mathrm{Nu}_{\mathrm{b}} d x$

And

$\overline{\mathrm{Nu}_{\mathrm{s}}}=\int_{0}^{H} \mathrm{Nu}_{\mathrm{s}} d y$

\section{Result AND Discussion}

\subsection{Verification of the Present Methodology}

The grid independent study has been made with different grids and biasing of an element to yield consistent values of Basak et al. (2006) and Lo et al. (2007). Computations are carried out for Raleigh numbers from $10^{3}$ to $10^{7}$ and $\operatorname{Pr}=0.7$. The present methodology is compared with that of Basak et al. (2006) and Lo et al. (2007). Basak et al. (2006) have studied for Ra $10^{3}$ to $10^{5}$ only for the cases of constant temperature and sinusoidally varying temperature at the bottom wall. Lo et al. (2007) have studied for $\mathrm{Ra}=10^{3}$ to $10^{7}$ for the cases of uniform temperature at vertical walls and adiabatic horizontal top and bottom walls. However, in the present case, linearly varying bottom wall temperature case is also included.

Different grid sizes of $31 \times 31,41 \times 41,51 \times 51$ and 61 $\mathrm{x} 61$ with uniform mesh has been studied. The grid $41 \mathrm{x}$ 41 with biasing ratio of 2 in both directions (The ratio of maximum cell to the minimum cell is 2 , thus making cells finer near the walls) gave results identical to that of $61 \times 61$. In view of this, $41 \times 41$ grid with double sided biasing ratio 2 is used in all further computations.

Figure 2a shows the convergence of the average Nusselt number at the heated surface with grid refinement for $\mathrm{Ra}=10^{5}$ of Lo et al. (2007). The grid used is $41 \times 41$ biasing ratio (BR) of 2 . It may be noted that Lo et al. (2007) have used a uniform mesh with grid size of $31 \mathrm{x}$ 31 in their study. However, in the present case, the study has been made for Rayleigh number ranging from $\mathrm{Ra}=10^{3}$ to $10^{7}$. In Fig. 2b, the average Nusselt number computed by the present methodology for the values of Ra ranging from $10^{3}$ to $10^{7}$ are compared with that of 


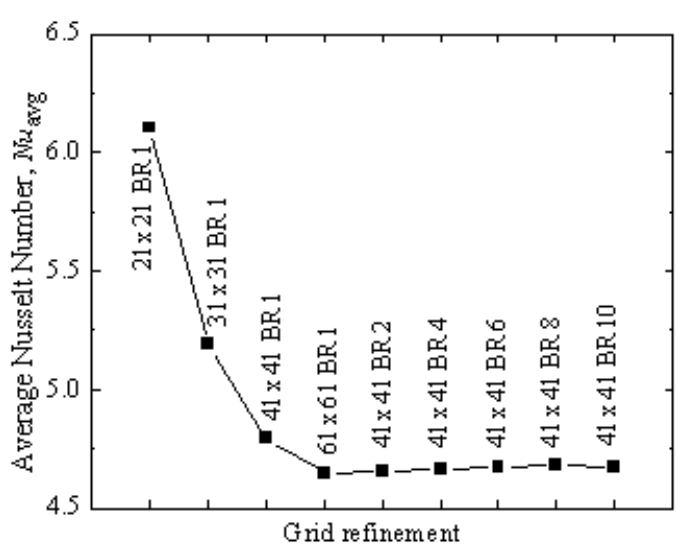

(a)

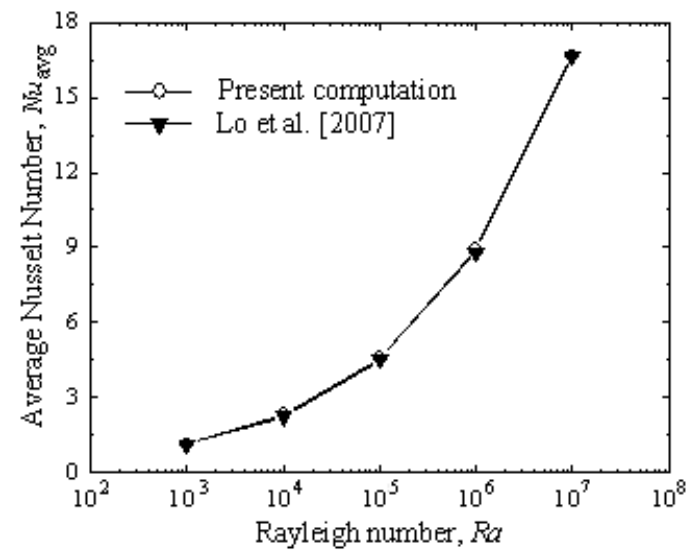

(b)

Fig. 2. Convergence of average Nusselt number with (a) Grid refinement (b) Lo et al. (2007)

Lo et al. (2007). It is observed that the agreement is found to be excellent which validates the present computations. It may be noted that Basak et al. (2006) have used a grid sizes of $41 \times 41$ with uniform mesh in their study. They have used constant and sinusoidal temperature at the bottom wall with two cold side walls. Identical to the case studied by Basak et al. (2006) has been investigated with a view to verify the present methodology.

Figure $3 \mathrm{a}$ and $3 \mathrm{~b}$ shows the streamline and temperature profiles for the case of constant temperature at the bottom wall for $\mathrm{Ra}=10^{3}$. In Fig. 3a the left portion shows the results of Basak et al. (2006) whereas right side shows the present results. There is a good agreement between two. Figure $3 \mathrm{~b}$ shows the temperature profiles for the same case. In view of the same temperature on both the cold walls, the temperature profile is symmetric about vertical line at the centre of the bottom wall. Left side portion represents the Basak et al. (2006) (continuous lines) results and right (dashed lines) side results are the present one. Again, one can see a good agreement between the two. Figures $3 \mathrm{c}$ and $3 \mathrm{~d}$ shows the stream lines and temperature profile for aspect ratio $(\mathrm{AR})=0.5$ for $\mathrm{Ra}=10^{3}$. It has been observed from the Fig. $3 \mathrm{c}$ that the magnitudes of stream functions are decreased with decrease of AR. In Fig. 3d the temperature profiles $\theta=0.6$ and above are spread for the entire length of the bottom hot wall. However, for $\theta=0.5$ and lower are symmetrical about vertical cold walls. Figure $4 \mathrm{a}$ and $4 \mathrm{~b}$
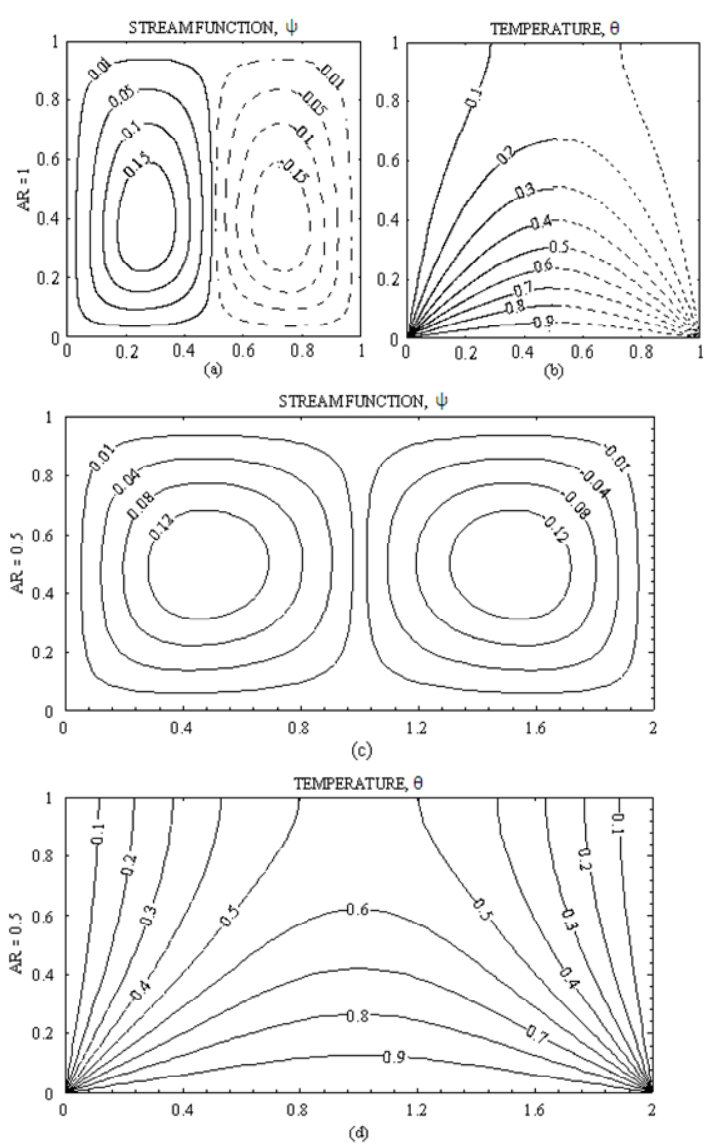

Fig. 3. Stream lines and temperature profiles - Constant temperature on bottom wall $-\mathrm{Ra}=10^{3}$
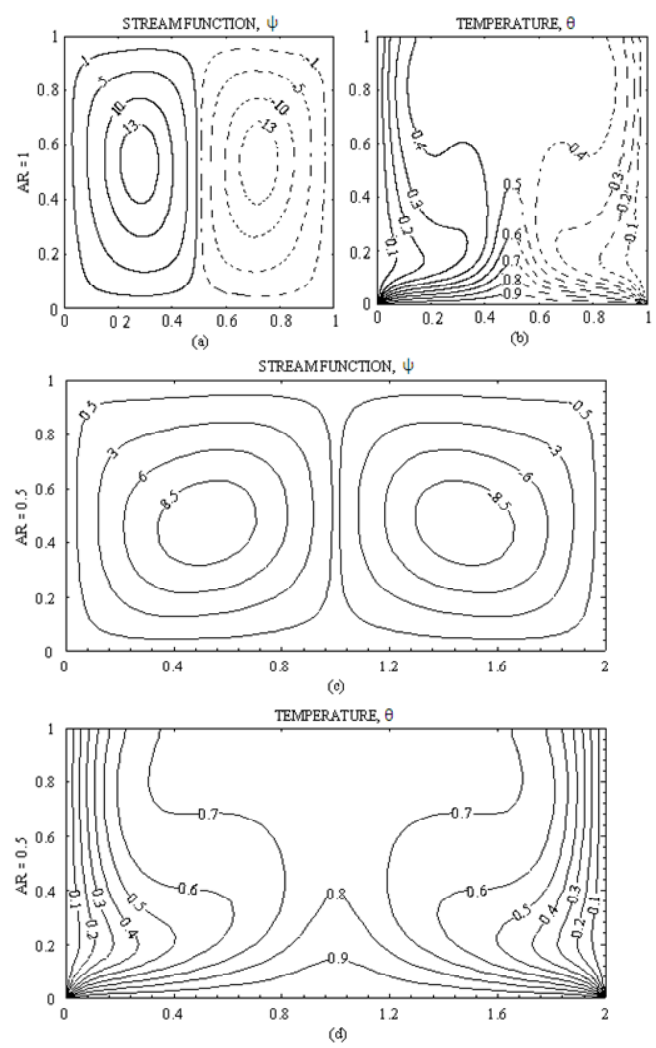

Fig. 4. Stream lines and temperature profiles - Constant temperature on bottom wall $-\mathrm{Ra}=10^{5}$ 
shows streamlines and temperature profiles of $\mathrm{AR}=1$ for the same case but for $\mathrm{Ra}=10^{5}$. Again, it is observed that there is a good agreement between results of Basak et al. (2006) and present one. Figures 4c and 4d shows stream lines and temperature profiles for $\mathrm{AR}=0.5$ for same Ra. It is observed from Fig. $4 \mathrm{c}$ that the magnitude of stream functions decreases with decrease of AR. The stream functions contours are slightly dragging towards the bottom corners and that of opposite corners are lifting vertically at the centre of the top adiabatic wall. Figure $4 d$ shows that, the more number of temperature curves are dragging and symmetrical at cold vertical walls as compared to $\mathrm{AR}=1$.
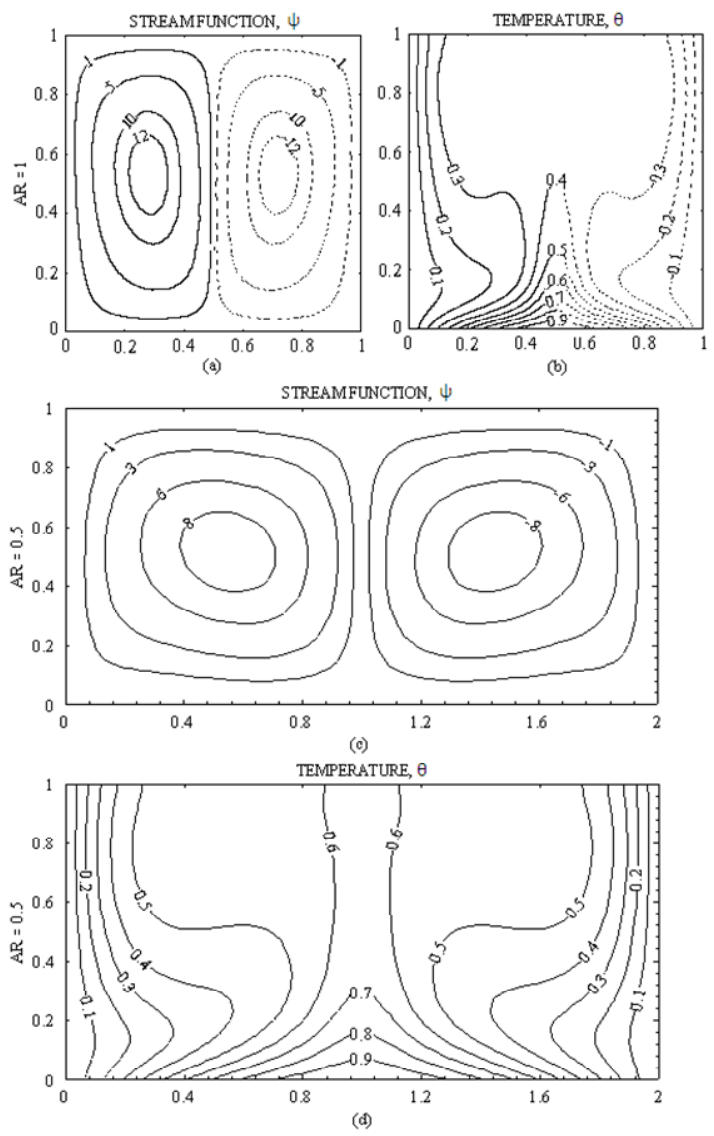

Fig. 5. Stream lines and temperature profiles -

Sinusoidal temperature on bottom wall - $\mathrm{Ra}=10^{5}$.

Figure 5 shows streamlines and temperature profile for same, when case of bottom wall subjected to sinusoidal temperature variation. Again it is seen that there is a very good agreement between the two cases. The magnitudes of stream functions decrease with decrease of AR as expected. However, it is observed from Fig. $5 \mathrm{c}$ that, the stream function are dragging towards top corners and inside bottom corners are to the centre of the bottom wall. By comparing temperature contours of constant and sinusoidal temperature at the bottom wall for $\mathrm{AR}=0.5$ with $\mathrm{Ra}=10^{5}$ that the discontinuities of temperature profiles for the case of constant temperature at bottom corners are removed successfully by replacing it by sinusoidal temperature. For constant temperature case (Fig. 4d), it is observed that $\theta=0.8$ and 0.9 span for the entire length of the bottom hot wall, whereas $\theta=0.7$ to 0.9 span for bottom hot wall for the sinusoidal case as seen from Fig. $5 \mathrm{~d}$.

\subsection{Uniform Temperature at the Bottom Wall}

The cavity used for the analysis is subjected to uniform temperature at the bottom wall. Computations are carried out for Rayleigh number ranging from $10^{3}$ to $10^{7}$. The aspect ratio is varied from 0.5 to 1 . As compared to Basak et al. (2006), new cases of $\mathrm{Ra}=10^{6}$ and $10^{7}$ for both $\mathrm{AR}=0.5$ and 1 are carried out. However, the stream functions and temperature profiles for the case of $10^{7}$ only are shown in Fig. 6.
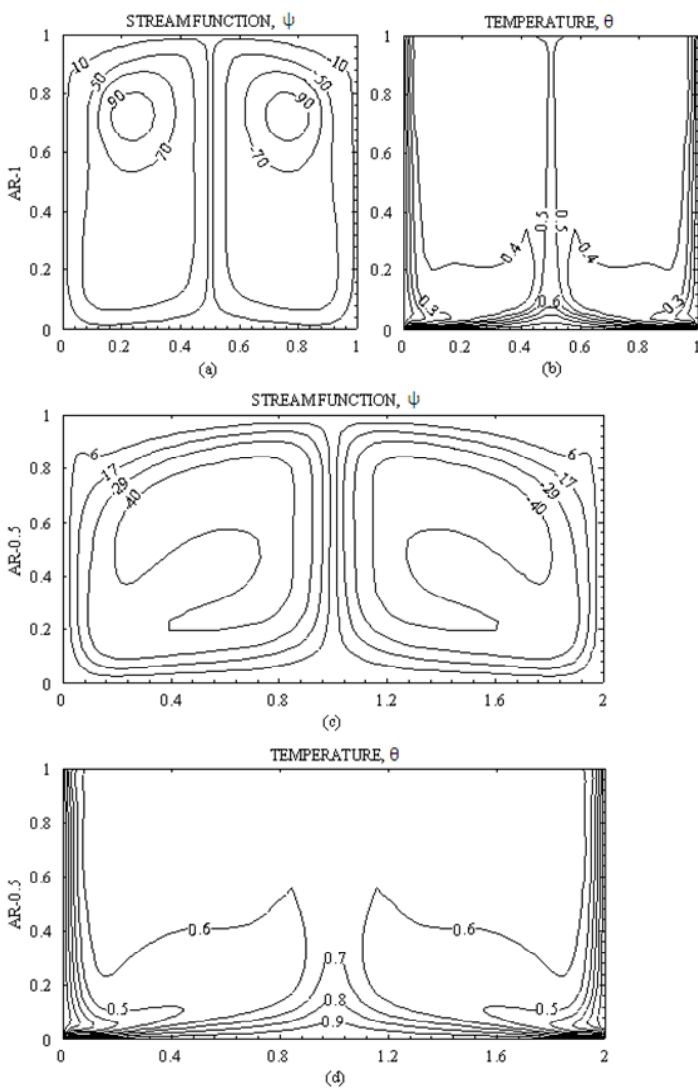

Fig. 6. Stream lines and temperature profiles - Constant temperature on bottom wall - $\mathrm{Ra}=10^{7}$

It is seen in the Fig. 6a that, the stream functions are forming circular cells at the top half of the vertical walls. Figure $6 \mathrm{~b}$ shows the temperature profiles. The temperature profiles are spread for the entire span of the bottom wall up to $\theta=0.6$, symmetric about vertical line and are settling nearer to bottom wall. The curves for $\theta$ $=0.4$ and lower values are concentrating nearer to the vertical cold walls. Figure $6 \mathrm{c}$ and $6 \mathrm{~d}$ shows the stream functions and temperature profiles of $\mathrm{AR}=0.5$ respectively. It is observed from Fig. $6 \mathrm{c}$ that the outside bottom contour of highest magnitudes bulging towards the centre of the cavity. The corner of the outermost curve is extending towards top corners of the cavity.

Figure 7 shows the variation of local Nusselt number for both bottom wall and side walls for the Rayleigh number ranging from $10^{3}$ to $10^{7}$ for the uniform temperature case. 


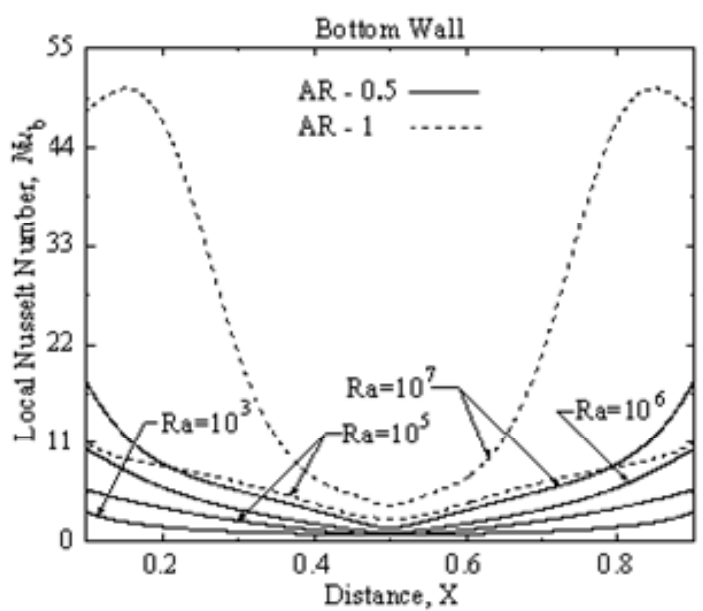

(a)

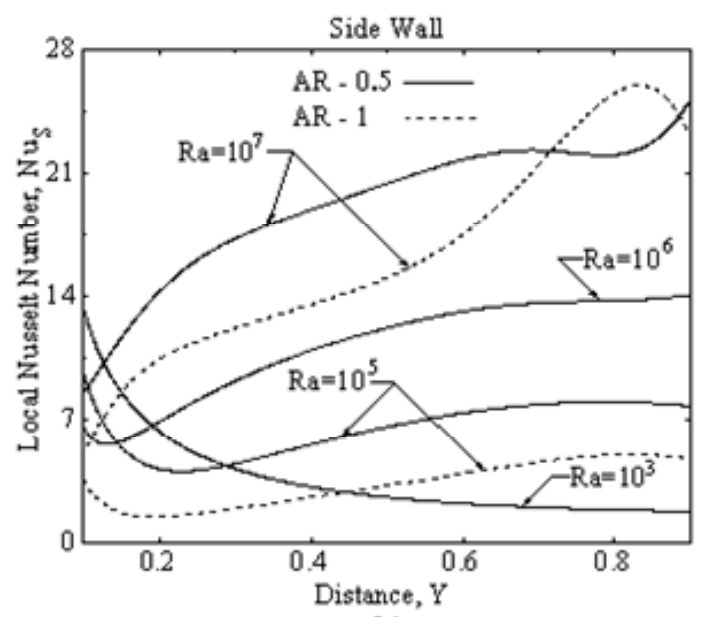

(b)

Fig. 7. Uniform temperature case - Local Nusselt numbers

As the Rayleigh number increases the non-uniformity of the local Nusselt number at the bottom wall also increases. As expected, the local Nusselt number at any given location increases with Rayleigh number. Figure $7 \mathrm{~b}$ shows the variation of local Nusselt number for side wall for Rayleigh number ranging from $10^{3}$ to $10^{7}$ for the case of uniform temperature. It is seen from Fig. $7 b$ that the local Nusselt number decreases monotonically along the side walls for $\mathrm{Ra}=10^{3}$ only. However, as the $\mathrm{Ra}$ increases to $10^{5}$, decreasing and increasing trends are observed for local Nusselt number. Similar trends have been observed by Basak et al. (2006) also. It is observed from Fig. 7a shows that, the local Nusselt number increases with increase of AR for bottom wall.

For the side wall the local $\mathrm{Nu}$ decreases with increase of $\mathrm{AR}$ for all $\mathrm{Ra}$. For $\mathrm{AR}=0.5$, the local $\mathrm{Nu}$ increases for $\mathrm{Ra}=10^{7}$ with distance up to $\mathrm{Y}=0.7$, then remains constant and increases further. For $\mathrm{AR}=1$, for $\mathrm{Ra}$ $=10^{7}$ the local $\mathrm{Nu}$ increases up to $\mathrm{Y}=0.8$ reaches a peak and decreases. For $\mathrm{Ra}=10^{6}$ and $\mathrm{AR}=1$, the local $\mathrm{Nu}$ increases up to $\mathrm{Y}=0.8$ and then decreases where as for $\mathrm{AR}=0.5$, the local $\mathrm{Nu}$ continuously increases. Figure $8 \mathrm{a}$ and $8 \mathrm{~b}$ shows the variation of average Nusselt number for the case of uniform temperature for both bottom wall and side walls respectively. It is observed that the average Nusselt number increases with Rayleigh number as expected. It is seen that the average Nusselt number increases with increase of AR for bottom wall. The average $\mathrm{Nu}$ for the side wall decreases with increase in $\mathrm{AR}$ up to $\mathrm{Ra}=5 \mathrm{x}$ $10^{5}$, whereas for $\mathrm{Ra}>5 \times 10^{5}$, the average $\mathrm{Nu}$ increases with AR.

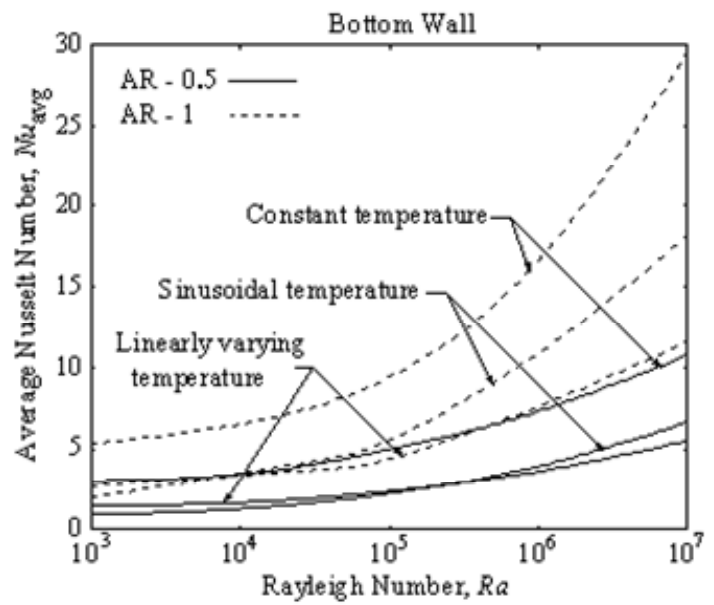

(a)

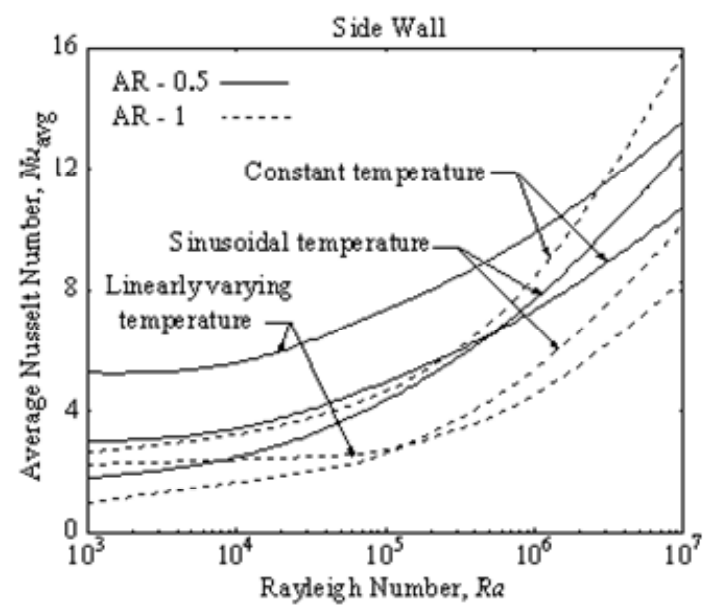

(b)

Fig. 8. Variation of average Nusselt number with Rayleigh number

\subsection{Sinusoidal Temperature at the Bottom Wall}

In reference to Basak et al. (2006), new cases of $\mathrm{Ra}=10^{6}$ and $10^{7}$ are carried out for $\mathrm{AR}=0.5$ and 1. However, the stream functions and temperature profiles for the case of $10^{7}$ only are shown in Fig. 9. The magnitudes of the stream functions for $\mathrm{Ra}=10^{7}$ shown in Fig. 9a are high compared to $\mathrm{Ra}=10^{5}$ (shown in Fig. 5). Figure 9c shows the temperature contours of $\mathrm{AR}=0.5$. It is observed that the inner cells becomes smaller in size and shifted to top of the cavity and others are spread for the entire cavity. The top ends of the outer cells are dragging towards the top corners of the cavity. Figures $9 \mathrm{~b}$ and $9 \mathrm{~d}$ shows the temperature contours for $\mathrm{Ra}=10^{7} .60 \%$ of the temperature contours are crowded near the bottom wall and spread over the entire length of the bottom wall for $\mathrm{AR}=1$ and $40 \%$ in case of $\mathrm{AR}=0.5$. 

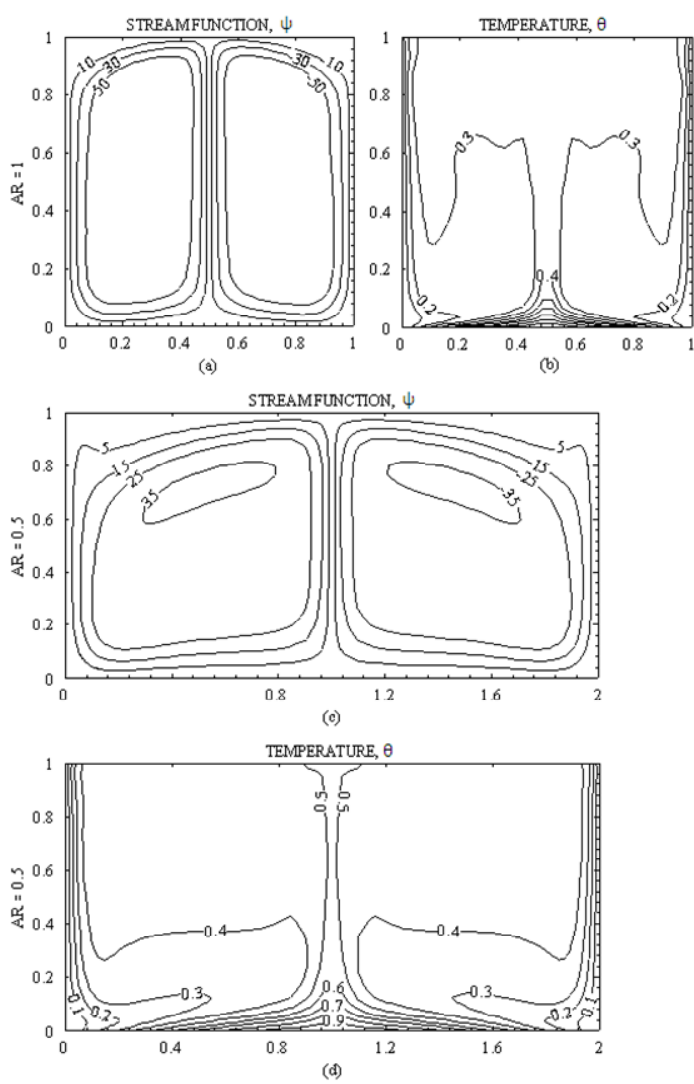

Fig. 9. Stream lines and temperature profiles Sinusoidal temperature on bottom wall $-\mathrm{Ra}=10^{7}$

Figure 10a shows the variation of local Nusselt number on bottom wall. As expected, it will be almost constant for $\mathrm{Ra}=10^{3}$. However, for $10^{5}, 10^{6}$ and $10^{7}$ there is a reduction towards the centre for both $\mathrm{AR}=0.5$ and 1 as expected. Figure $10 \mathrm{~b}$ shows the variation of local Nusselt number for the side wall. For $\mathrm{Ra}=10^{3}$ local Nusselt number decreases monotonically along the length. For $\mathrm{Ra}=10^{5}$ slightly decreasing and increasing trend is observed. For other values of $\mathrm{Ra}$, and $\mathrm{AR}=$ 0.5 , increasing trend has been observed for entire length of the side wall. However, for $\mathrm{Ra}=10^{6}$ and $10^{7}$, for $\mathrm{AR}=1$ the local $\mathrm{Nu}$ increases almost up to $\mathrm{Y}=0.8$, reaches a peak and decreases. It is seen from Fig. 10 that the local Nusselt number increases with increase of AR for bottom wall and decrease for that of side wall. Figure 8 also shows the variation of average Nusselt number against Rayleigh number. It is observed that the values are lower than uniform bottom wall temperature case. The average Nusselt number increases with increase of AR for bottom wall and decrease for that of side wall as expected.

\subsection{Linearly Varying Temperature at the Bottom Wall}

Stream function contours and isotherms are shown in Figs. 11 to 13 for $\mathrm{Ra}=10^{3}, 10^{5}$ and $10^{7}$ respectively. When, the bottom wall is subjected to linearly varying temperature. A finite discontinuity in Dirichlet type boundary conditions exist for constant temperature at both side walls and bottom wall. In contrast, the linearly varying temperature removes the singularities at one edge of the bottom wall and profiles are not symmetric about central vertical line.

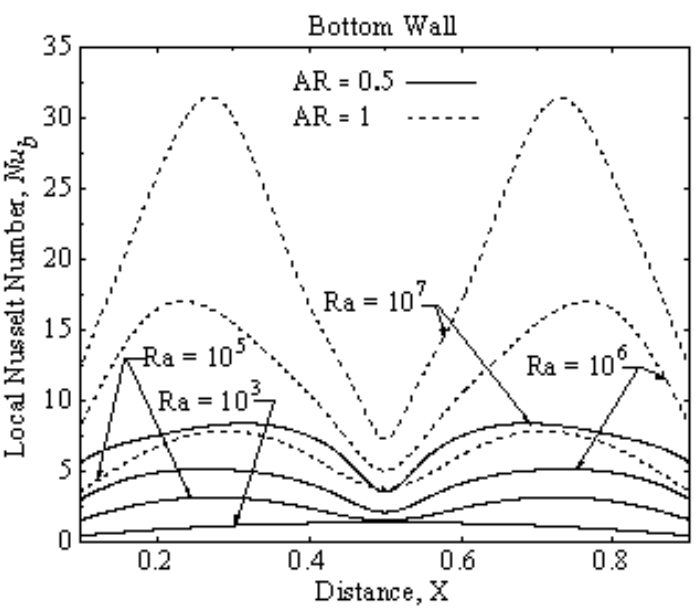

(a)

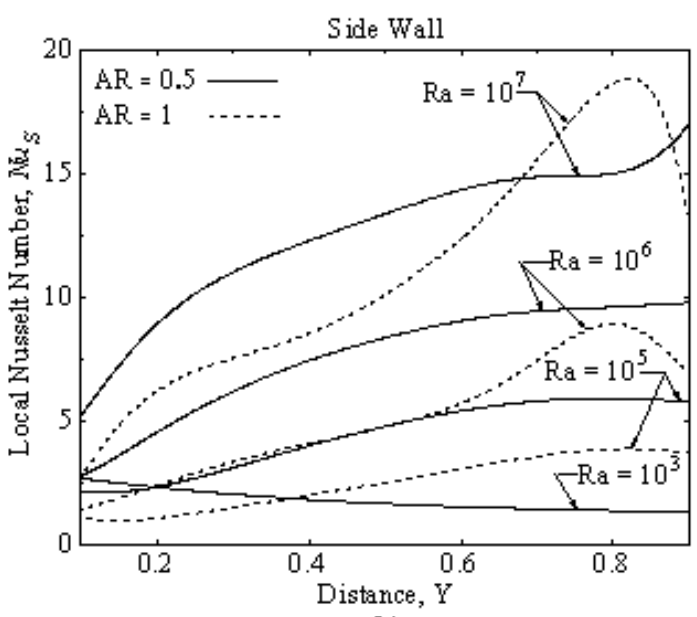

(b)

Fig. 10. Local Nusselt numbers for sinusoidal temperature case.

The temperature at bottom wall is linearly varying temperature and a maximum temperature occurs at the right wall. It is seen that the two cells in Fig. 11a are of different sizes and the value of $\Psi$ is small for $\mathrm{Ra}=10^{3}$. Figure $11 \mathrm{~b}$ shows the temperature profiles and they are concentrated towards the right side. It is observed from Fig. $11 \mathrm{c}$ that for $\mathrm{AR}=0.5$, the cells of the stream functions are dragging along the longer side of the cavity and right cells are concentrated at right side of the cavity. The temperature contours of $\mathrm{AR}=0.5$ shown in Fig. 11d. The temperature contours $\theta=0.1$ and 0.2 are concentrating at the side walls as compared to $\mathrm{AR}=1$.

Figures $12 \mathrm{a}$ and $12 \mathrm{~b}$ shows the streamlines and temperature profiles for $\mathrm{Ra}=10^{5}$ with $\mathrm{AR}=1$. It is seen from Fig. 12a that, the left cells are extended to right. It is observed that the temperature contours are not similar with $\theta=0.1$ and 0.2 and are not symmetrical near side walls of the enclosure as that of the uniform temperature case. The other temperature contours, $\theta=$ 0.3 and above are smooth curves. For $\mathrm{AR}=0.5$, the left cells are extended to right and central cells are elliptical in shape. 

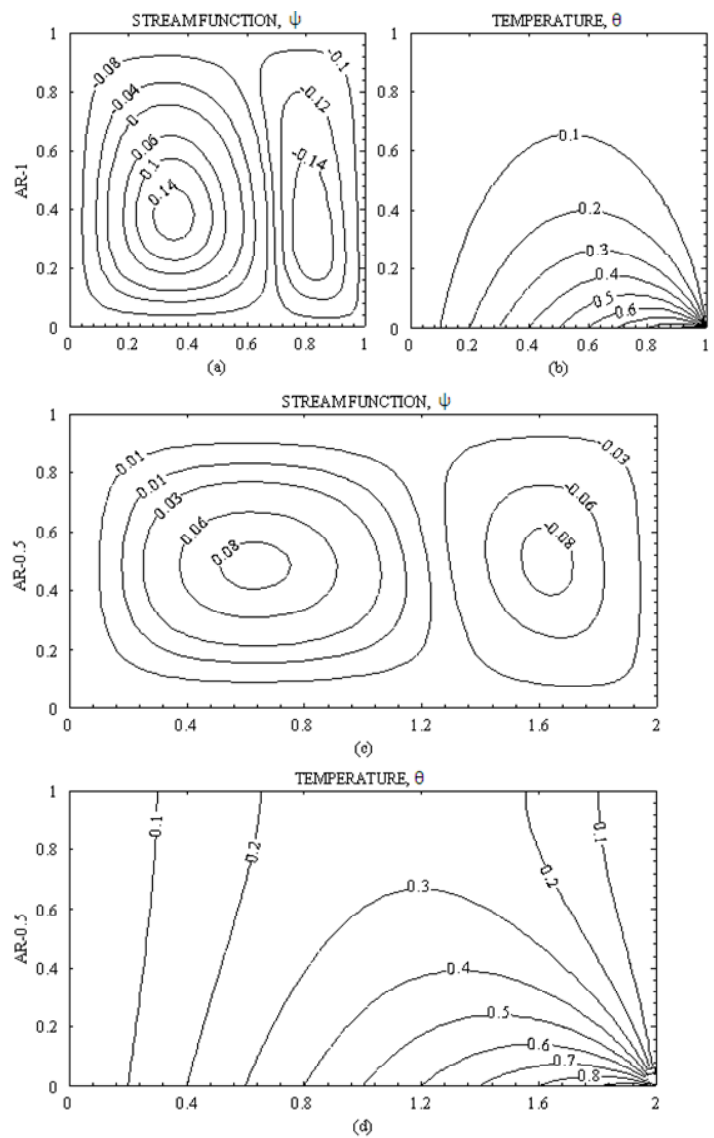

Fig. 11. Stream lines and temperature profiles Linearly varying temperature on bottom wall $-\mathrm{Ra}=10^{3}$
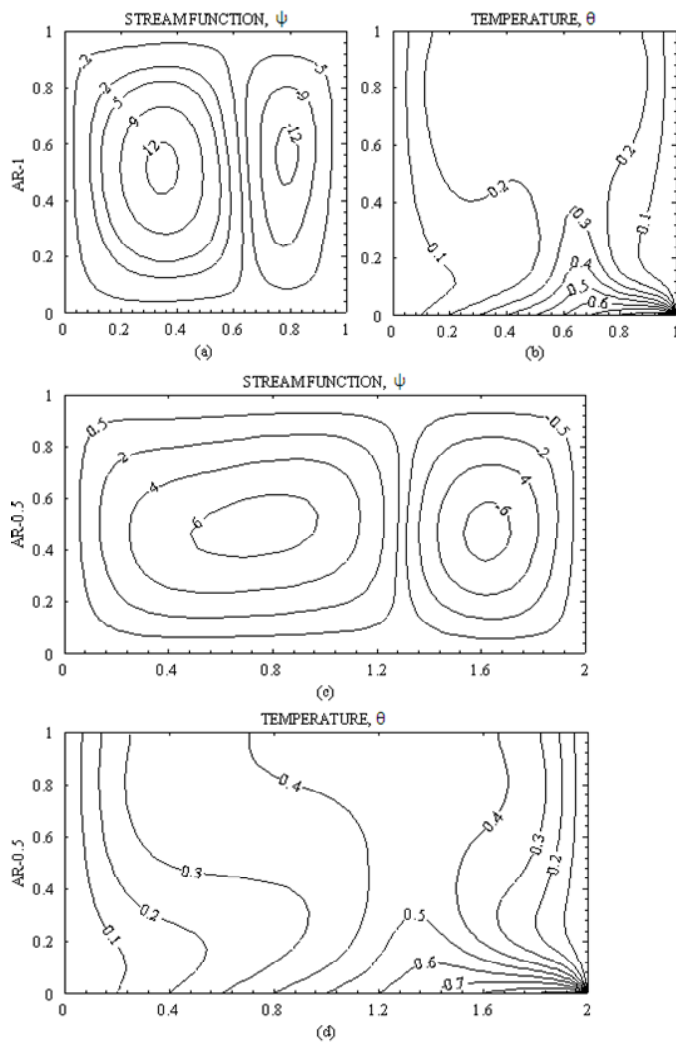

Fig. 12. Stream lines and temperature profiles Linearly varying temperature on bottom wall $-\mathrm{Ra}=10^{5}$
Figure 13 shows the streamlines and temperature profiles for $\mathrm{Ra}=10^{7}$ for both $\mathrm{AR}=1$ and 0.5 . It is observed from Fig. 13a that the right cell moves to left in the top whereas left cell extends to right in the bottom. Stream function values have increased substantially showing strong circulations. Figure $13 \mathrm{~b}$ shows a distorted temperature profiles due to convection. It is seen that the temperature profiles concentrate towards right bottom corner. It is observed from Fig. $13 \mathrm{c}$ that for $\mathrm{AR}=0.5$ the top corners of the left cells extended to right side and smaller cells are moving upwards. The right cells are smaller in size. 60 $\%$ of the temperature contours (shown in Fig. 3d) are smooth curves and concentrated at bottom of the right side wall.
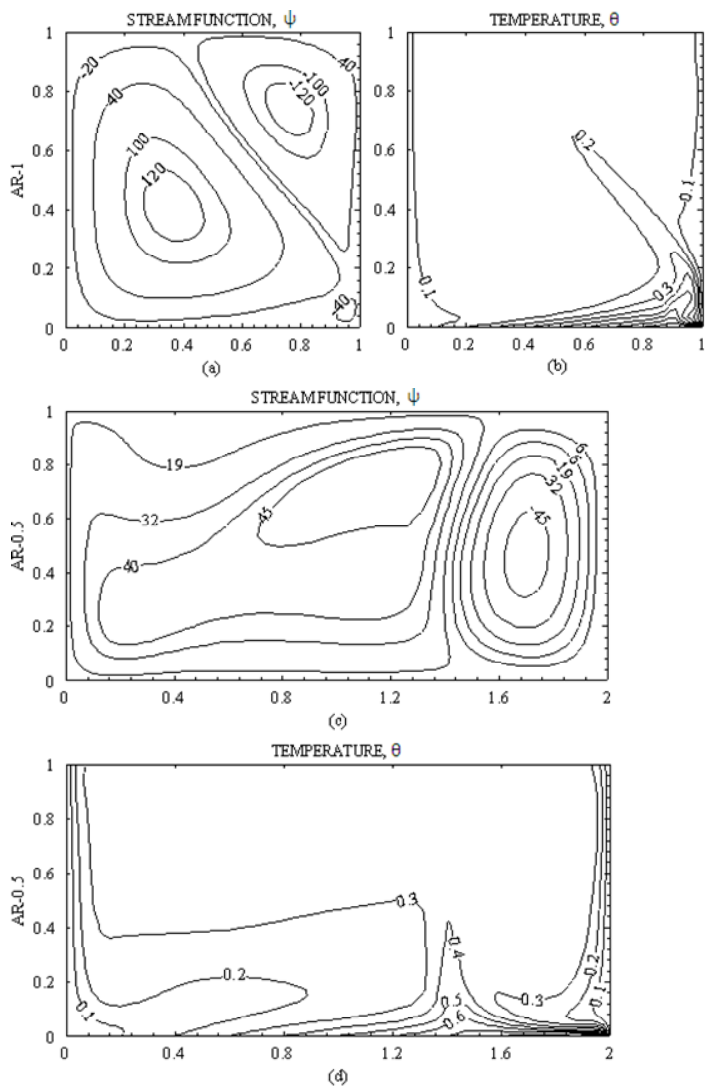

Fig. 13. Stream lines and temperature profiles Linearly varying temperature on bottom wall $-\mathrm{Ra}=10^{7}$

Figure 14 shows the variation of local Nusselt number along the bottom and side walls. For $\mathrm{Ra}=10^{3}$, the local Nusselt number decreases monotonically for bottom wall. For $\mathrm{AR}=1$, the local Nusselt number for $\mathrm{Ra}=$ $10^{5}$ and $10^{7}$ show increasing, decreasing and again increasing trend. However, for $\mathrm{AR}=0.5$ decreasing, increasing and again increasing trend is observed. For side walls $\mathrm{Ra}=10^{3}$ with $\mathrm{AR}=1$, the local Nusselt number decreases monotonically whereas for $\mathrm{Ra}=10^{5}$ the local Nusselt number decreases and then increases. However, for $\mathrm{AR}=0.5$ and 1 with $\mathrm{Ra}=10^{7}$ increasing and decreasing tends are observed. For $\mathrm{AR}=0.5, \mathrm{Ra}=$ $10^{5}$, local Nusselt number decreases, attains a minimum and then increases to attain its maximum value and again decreases near the right hand side wall. Figure 8 also shows the variation of average Nusselt number with Rayleigh number. 
Table 1 Correlation of Nusselt number with Rayleigh number

\begin{tabular}{|c|c|c|c|c|c|c|c|c|}
\hline \multirow{2}{*}{ Heating type } & \multirow{2}{*}{$\begin{array}{l}\text { Aspect } \\
\text { ratio } \\
(A R)\end{array}$} & \multirow{2}{*}{$\begin{array}{c}\text { Rayleigh } \\
\text { number range }\end{array}$} & \multicolumn{3}{|c|}{ Bottom Wall } & \multicolumn{3}{|c|}{ Side Wall } \\
\hline & & & Correlation & $R^{2}$ & $\begin{array}{c}\% \\
\text { Error }\end{array}$ & Correlation & $R^{2}$ & $\begin{array}{c}\% \% \\
\text { Error }\end{array}$ \\
\hline \multirow{4}{*}{$\begin{array}{l}\text { Uniform } \\
\text { temperature }\end{array}$} & 0.5 & $10^{4}$ to $10^{7}$ & $\mathrm{Nu}_{\text {avg }}=0.666 \mathrm{Ra}^{0.171}$ & 0.999 & $<1.5$ & $\mathrm{Nu}_{\text {avg }}=1.275 \mathrm{Ra}^{0.175}$ & 0.999 & $<1.0$ \\
\hline & \multirow{3}{*}{1} & $5 \times 10^{3}$ to $10^{5}$ & $\mathrm{Nu}_{\text {avg }}=1.611 \mathrm{Ra}^{0.145}$ & 1.000 & $<1.0$ & $\mathrm{Nu}_{\text {avg }}=0.885 \mathrm{Ra}^{0.136}$ & 0.999 & $<1.0$ \\
\hline & & $10^{5}$ to $10^{7}$ & $\mathrm{Nu}_{\text {avg }}=0.397 \mathrm{Ra}^{0.267}$ & 1.000 & $<2.0$ & $\mathrm{Nu}_{\text {avg }}=0.145 \mathrm{Ra}^{0.289}$ & 0.999 & $<2.0$ \\
\hline & & $5 \times 10^{3}$ to $10^{7}$ & $\mathrm{Nu}_{\text {avg }}=0.799 \mathrm{Ra}^{0.219}$ & 0.992 & $<3.0$ & $\mathrm{Nu}_{\mathrm{avg}}=0.347 \mathrm{Ra}^{0.229}$ & 0.997 & $<3.0$ \\
\hline \multirow{4}{*}{$\begin{array}{l}\text { Sinusoidal } \\
\text { temperature }\end{array}$} & 0.5 & $10^{4}$ to $10^{7}$ & $\mathrm{Nu}_{\text {avg }}=0.121 \mathrm{Ra}^{0.247}$ & 0.999 & $<1.5$ & $\mathrm{Nu}_{\text {avg }}=0.240 \mathrm{Ra}^{0.246}$ & 0.999 & $<1.5$ \\
\hline & \multirow{3}{*}{1} & $2 \times 10^{4}$ to $10^{5}$ & $\mathrm{Nu}_{\mathrm{avg}}=0.298 \mathrm{Ra}^{0.249}$ & 0.999 & $<1.0$ & $\mathrm{Nu}_{\mathrm{avg}}=0.154 \mathrm{Ra}^{0.242}$ & 0.999 & $<1.0$ \\
\hline & & $10^{5}$ to $10^{7}$ & $\mathrm{Nu}_{\text {avg }}=0.272 \mathrm{Ra}^{0.261}$ & 0.998 & $<2.0$ & $\mathrm{Nu}_{\text {avg }}=0.072 \mathrm{Ra}^{0.305}$ & 0.999 & $<2.0$ \\
\hline & & $2 \times 10^{4}$ to $10^{7}$ & $\mathrm{Nu}_{\text {avg }}=0.248 \mathrm{Ra}^{0.267}$ & 0.999 & $<2.9$ & $\mathrm{Nu}_{\text {avg }}=0.088 \mathrm{Ra}^{0.292}$ & 0.998 & $<3.0$ \\
\hline \multirow{3}{*}{$\begin{array}{l}\text { Linearly } \\
\text { varying } \\
\text { temperature }\end{array}$} & 0.5 & $10^{4}$ to $10^{7}$ & $\mathrm{Nu}_{\text {avg }}=0.288 \mathrm{Ra}^{0.181}$ & 0.997 & $<2.0$ & $\mathrm{Nu}_{\text {avg }}=1.553 \mathrm{Ra}^{0.133}$ & 0.998 & $<1.5$ \\
\hline & \multirow{2}{*}{1} & $10^{5}$ to $10^{7}$ & $\mathrm{Nu}_{\text {avg }}=0.374 \mathrm{Ra}^{0.213}$ & 0.998 & $<3.0$ & $\mathrm{Nu}_{\text {avg }}=0.050 \mathrm{Ra}^{0.287}$ & 0.998 & $<3.0$ \\
\hline & & $2 \times 10^{4}$ to $10^{7}$ & $\mathrm{Nu}_{\mathrm{avg}}=0.378 \mathrm{Ra}^{0.212}$ & 0.997 & $<3.0$ & $\mathrm{Nu}_{\mathrm{avg}}=0.053 \mathrm{Ra}^{0.284}$ & 0.998 & $<3.0$ \\
\hline
\end{tabular}

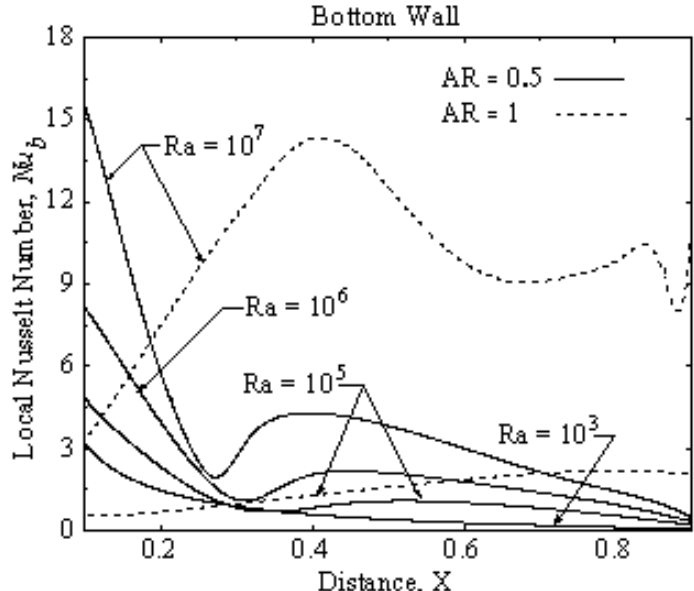

(a)

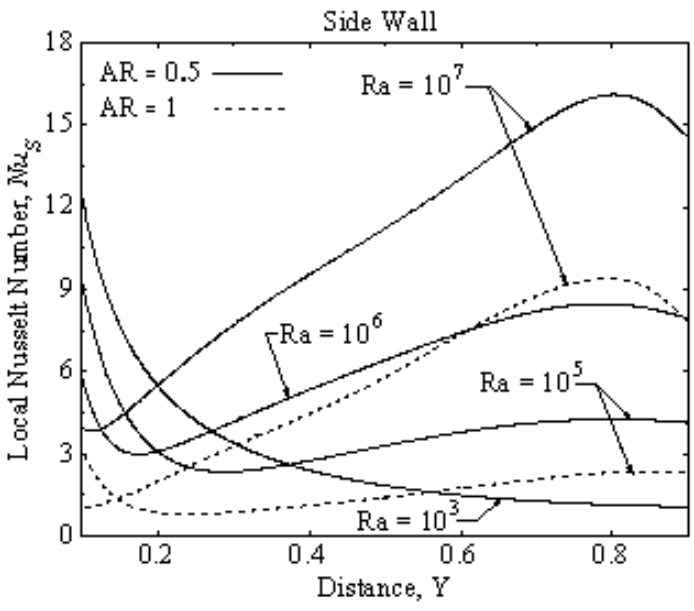

(b)

Fig. 14. Local Nusselt numbers for linearly varying temperature case.

For linearly varying temperature on the bottom wall, the variation of average Nusselt number increases with increase of Rayleigh number as expected. However, it increases with increase of $\mathrm{AR}$ at bottom wall and decreases for that of side wall. The overall effect on the heat transfer rate is shown in Figs. 8a and $8 \mathrm{~b}$ in which the distribution of the average Nusselt number for both bottom and side walls respectively are plotted versus the logarithmic Rayleigh number. In the present investigation, the log-log plot for average Nusselt number versus Rayleigh number for convection dominant regimes are plotted and studied. A least square curve is fitted and the overall error is within 3\%. However, the present studies are extended up to $10^{7}$. The error involved is tabulated in the Table 1. It has been observed from the table that the error involved increases with increase of Rayleigh number. The correlations derived in the present study are given in Table 1.

\subsection{Correlations of average Nusselt number with Rayleigh number}

\subsubsection{Case (a) Uniform Temperature}

In the present study, for AR-1, the correlation obtained for $\operatorname{Ra} 5 \times 10^{3}$ to $10^{5}$ is differing from that of Basak et al. (2006) utmost by $0.675 \%$. The maximum error involved in correlating average Nusselt number with Rayleigh number is less than $2 \%$ in the range of $\mathrm{Ra} 10^{5}$ to $10^{7}$. For combined case i.e. for Rayleigh number ranging from $5 \times 10^{3}$ to $10^{7}$ the utmost error is $3 \%$. However, for $\mathrm{AR}=0.5$, for Ra ranging from $2 \times 10^{4}$ to $10^{7}$, it is seen from the Table 1 that the error involved will not exceed $1.5 \%$.

\subsubsection{Case (b) Sinusoidal Temperature}

The correlation presented in the Table 1 is for sinusoidal temperature variation at bottom wall is very close to that of Basak et al. (2006) with a maximum error of $1 \%$ in which studies are limited to $A R=1$. However, the error increases to a maximum of $3 \%$ when Ra ranges from $2 \times 10^{4}$ to $10^{7}$. It is seen from the Table 1 that for AR-0.5, the error involved will not exceed $1.5 \%$. 


\subsubsection{Case (c) Linearly Varying Temperature}

The correlation presented in the Table 1 is for aspect ratio 1 and 0.5 . For $A R=1$ subjected to linearly varying temperature at bottom wall in the range of Ra $10^{5}$ to $10^{7}$ exhibits a maximum error of $3 \%$. It is also observed that when the range of $\mathrm{Ra}$ is from $\mathrm{Ra} 2 \times 10^{4}$ to $10^{7}$ the maximum error is $3 \%$ for the bottom wall. However for the side wall the maximum error is seen to be $3 \%$. It is observed from the analysis that for $\mathrm{AR}=$ 0.5 , the convection is dominating for $\mathrm{Ra}=10^{5}$ and above. The error involved is less compared to other cases studied. Maximum error involved is less than $1.5 \%$.

\section{Conclusion}

The effect of various types of temperature boundary conditions at the bottom wall like uniform, sinusoidal and linearly varying temperature with constant side cold walls is investigated for both $\mathrm{AR}=0.5$ and 1 . From the study it has been observed that the average Nusselt number for the case of uniform bottom wall is more than that of sinusoidally varying and linearly varying temperature profile. The average Nusselt number increases with increase of AR for bottom wall. The average $\mathrm{Nu}$ decreases for side wall for a given Rayleigh number. Except for $\mathrm{Ra}=10^{7}$ in which case average $\mathrm{Nu}$ decreases with $\mathrm{AR}$ up to $\mathrm{Ra}=5 \times 10^{5}$ and then reverses the trend.

\section{REFERENCES}

Basak, T., S. Roy and A.R. Balakrishnan (2006). Effect of thermal boundary conditions on natural convection flows with in a square cavity. International Journal of Heat and Mass Transfer 49, 4525-4535.

Batchelor, G.K. (1993). An introduction to fluid dynamics. Cambridge University Press.

Chadwick, L., B.M. Webb and R. Ricci (1991). Experimental and Numerical investigations on natural convection from two dimensional discrete heat sources in a rectangular enclosure. Int. J. Heat and mass transfer 34, 1679-1693.

Corcione, M. (2003). Effects of the thermal boundary conditions at the sidewalls upon natural convection in rectangular enclosures heated from below and cooled from above. Int. J. Therm. Sci. 42, 199208.

Cormack, D.E., L.G. Leal and J.H. Seinfeld (1974). Natural convection in shallow cavity with differentially heated end walls. Part 2, Numerical solutions. J. Fluid Mech. 65, 231-246.

Cotton, I. (1978). Natural convection in enclosures. Proceedings of the $6^{\text {th }}$ International Heat Transfer Conference 61979, Toronto, 13-43.

Dehghan, A.A. and M. Behnia (1996). Combined natural convection-conduction and radiation heat transfer in a discretely heated open cavity. J. Heat Transfer, Transactions of ASME 118, 56-64.
Dixit, H.N. and V. Babu (2006). Simulation of high Rayleigh number natural convection in a square cavity using the lattice Boltzmann method. Intl. J. Heat and Mass Transfer 49, 727-739.

Eckert, E.R.G. and W.O. Carlson (1961). Natural convection in an air layer enclosed between two vertical plates with different temperatures. Int. J. Heat Transfer 2, 106-120.

Emery, N. and C. Chu (1965). Heat transfer across vertical layers. J. Heat Transfer 87, 110-114.

Erenburg, V., A.Y. Gelfgat, E. Kit, P.Z. Bar-Yoseph and A. Solan (2003). Multiple states, stability and bifurcations of natural convection in a rectangular cavity with partially heated vertical walls. J. Fluid Mechanic 492, 63-89.

Hall, J.D., A. Bejan, and J.B. Chaddock, (1988). Transient natural convection in a rectangular enclosure with one heated side wall. Int. J. Heat Fluid Flow 9, 396-404.

Jaluria, Y. (1980). Natural convection heat and mass transfer. Pergamon, Oxford, 209-235.

Lage, J.L. and A. Bejan (1993). The resonance of natural convection in an enclosure heated periodically from the side. Int. J. Heat Mass Transfer 36, 2027-2038.

Lage, J.L. and A. Bejan (1991). The Ra - Pr domain of laminar natural convection in an enclosure heated from the sides. Numerical Heat Transfer Part A $19,21-41$.

Leong, W.H., K.G.T. Hollands and A.P. Brunger (1999). Experimental Nusselt numbers for a Cubical-cavity benchmark problem in natural convection. Int. J. Heat Mass Transfer 42, 19791989.

Lo, D.C., D.L. Young and C.C. Tsai (2007). High resolution of $2 \mathrm{D}$ natural convection in a Cavity by the DQ method. Journal of Computational and Applied Mathematics 203, 219-236.

Nicolette, V.F., K.T. Yang and J.R. Lloyd (1985). Transient cooling by natural convection in a twodimensional square enclosure. Int. J. Heat Mass Transfer 28, 1721-1732.

Ostrach, S. (1988). Natural convection in enclosures. Journal of Heat Transfer 110, 1175-1190.

Ostrach, S. (1970). An experimental investigation of natural convection in a horizontal Cylinder. $J$. Fluid Mech 44(2c), 545-561.

Refai Ahmed, G. and M.M. Yovanovich (1991). Influence of discrete heat source location on convection heat transfer in a vertical square enclosure. ASME J. Electronic Packaging 113, 268-274. 
Aswatha et al. / JAFM, Vol. 5, No. 2, pp. 43-53, 2012.

Sarris, I.E, I. Lekakis and N.S. Vlachos (2002). Natural convection in a $2 \mathrm{D}$ enclosure with sinusoidal upper wall temperature. Numerical Heat Transfer A 42, 513-530.

Wakashima, S. and T.S. Saitoh (2004). Benchmark solutions for natural convection in a cubic cavity using the high-order time-space methods. Int. J. Heat Mass Transfer 47, 853-864.

Weinbaum, S. (1964). Natural convection in horizontal cylinders. J. Fluid Mech.18, 409-448.

Xia, C. and J.Y. Murthy (2002). Buoyancy-driven flow transitions in deep cavities heated from below. ASME Trans. J. Heat Transfer 124, 650-659.

Yang, K.T. (1988). Transitions and bifurcations in laminar buoyant flows in confined enclosures. Journal of Heat Transfer 110, 1191-1204. 